\title{
Risk Perception of Individual Suppliers in E-Commerce Transactions
}

\author{
Yinping Kong ${ }^{* \# 1}$, Yiwen Chen ${ }^{* 2}$, Shuai $\mathrm{Wu}^{* 3}$, Xuan Jiao ${ }^{* 4}$ \\ * Institute of Psychology, Chinese Academy of Sciences \\ 4A Datun Road, Chaoyang District, Beijing, P. R. China

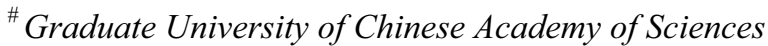 \\ 19A Yuquan Road, Shi Jingshan District, Beijing, P. R. China

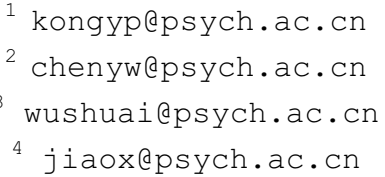

Abstract-This study aimed to explore the relationship between three kinds of risk characteristics, anxiety, controllability and predictability respectively, and their effects on total risk perception, and their relationship with risk-coping behaviors in e-commerce transactions. 174 individual suppliers participated in the survey. Results indicated that: a) the correlation between controllability and predictability was high, while anxiety remained independently; b) the risk source factors of two risk characteristics were different; c) the anxiety influenced the total risk most; d) individual suppliers tended to take coping risk behaviors as much as possible. Also, part of the risk coping behaviors has significant correlation with risk characteristics.

\section{INTRODUCTION}

C2C (Consumer to Consumer) e-commerce transaction has emerged that allowed individual suppliers sell new products and services or exchange secondhand goods to one-another. With the rapid development of Internet and e-commerce during the last decade, $\mathrm{C} 2 \mathrm{C}$ transaction has also been achieved great development and became kind of important economic activity manner in this information ages. $\mathrm{C} 2 \mathrm{C}$ confers benefits on both consumers and individual suppliers, but it also magnifies uncertainties involved with certain purchase processes, leading to perceived risks. Due to the lack of government management and scientific research, there are still some problems, product risk and security risk which sellers in the $\mathrm{C} 2 \mathrm{C}$ e-commerce transactions must bear, e.g. integrity problems, poor second-hand goods, simple payment means, slack goods delivery, inadequate laws and policies, etc [1]. The above problems and risks will definitely baffle $\mathrm{C} 2 \mathrm{C}$ ecommerce transactions. Although the use of $\mathrm{C} 2 \mathrm{C}$ e-commerce transaction is extremely common, surprisingly little empirical research has been undertaken by consumer scientists and ecommerce managers. So in this paper it is necessary to explore the risk perception and risk source of individual suppliers in the e-commerce transactions in order to get better understand of the risk characteristics and risk coping behaviors of the individual suppliers and to get a more stable risk management plan.

$\overline{978-1-4244-4158-7 / 09 / \$ 25.00 ~ @ 2009 ~ I E E E ~}$
Risk perception is a kind of psychological concept that means individuals' feeling and cognition to kinds of external risks. It also focuses on how personal experience that derived from intuitionist judgments and subjective feelings affect individuals' perception [2]. Research on risk perception has its origin in research on judgment and decision, and it actually begins with the research on gambling. Mun concludes three kinds of risk perception research paradigms [3]: technology paradigm, psychometrical paradigm and social-cultural paradigm.

Applying technology paradigm, one can get measurable and acceptable risk levels which can be generalized to different kinds of dangerous circumstance. This paradigm contains comparative risk, revealed preferences and risk/benefit analysis, and it assumes that human beings are fully rational and make decisions according to actual level of risk rather than the perceived level of risk [4]. Actually, the above assumption is difficult to come into existence, and the interoperability of the technology paradigm is weak and data collection is also difficulty.

Psychometrical paradigm comes from stated preference paradigm developed by Starr [5]. Its basal hypotheses are: 1) perceived risk can be forecasted and measured; 2) The meanings of risk are different for various people; 3) People can evaluate especial harm according to some risk characteristics, e.g. controllability, fearfulness and disaster. It applies traditional questionnaire form to get information directly from participants and conclude subjective perceived risk and risk characteristics of actual risk consequently. Stated preference paradigm can't elicit the relationship between perceived risk and actual risk level directly, but it can deduce cognition and perception process of actual risk by comparing subjective risk level to risk characteristics of different external risk sources, and then predict their future behavior. However, some researchers, e.g. Laird argue that the paradigm neglects the effect of social and political circumstances on risk perception [6]. Krimsky and Plough [7] also think that, we can't understand risk perception without complex social frame.

To offset the limitation that psychometrical paradigm neglects social and cultural circumstances, social-cultural 
paradigm introduces social and cultural theories into risk perception, and tries to explain and predict how dangerous people will feel and perceive in different potential risks by applying cultural adherence, social learning, etc [8].

Psychometrical paradigm is the most commonly used compared to the two other paradigms mentioned above. As we also mentioned, psychometrical paradigm can't elicit the relationship between perceived risk and actual risk level directly, and Kahneman and Tversky [9], [10] suggest the prospect theory to account for the limitation. Prospect theory applies a function to explain the relationship between actual risk and perceived risk, and it fixes the possibility and loss number to a given actual risk, and asks participants a series of questions about probability to elicit the function of perceived risk. But this kind of experiment requires necessary knowledge of probability, and it is easy to fatigue the participants and is not suitable for large-scale surveys. Furthermore, some researchers suggest that the prospect theory need further modification, e.g. Stewart [11] proves that prospects are not unattached, contrary to the hypothesis of prospect theory.

Risk characteristics, which are also called personality of risk, are one of the main contents of research on risk perception applying psychometrical paradigm. Researches focus on different risks and so refer to different risk sources, but risk characteristics have something in common, they can respect on the extent of perceived risk on different dimensions of risks respectively.

Slovic etc. [12] was the first to apply personality to risk events, e.g. unconstraint, controllability, lethality, effect, etc, and they identified two factors (dimensions) among risk characteristics of the relative research. One factor is called anxious risk, e.g. risk of anxiety, risk of global calamity, risk of lethality outcome, etc. The second factor is called unknown risk, e.g. unobservable risk, unconscious risk, undiscovered scientific risk, etc. However, Slovic and Xie etc [2], [13] suggested one could achieve better understanding of the structure and hierarchy of risk perception by focusing on several risk characteristics as a whole at the same time.

Despite lots theoretic and empirical research on risk perception mentioned above, there is little concerned about risk perception of individual suppliers in the e-commerce transactions. Furthermore, little is known about risk perception of Chinese individual suppliers especially. Given the newness of the $\mathrm{C} 2 \mathrm{C}$ e-commerce transactions and the likely roles of risk perception, the research is needed to better understand the source of risk and risk characteristics of individual suppliers in $\mathrm{C} 2 \mathrm{C}$ transactions, and their risk management behaviors. Particularly, the purpose of this study is to identify how individual suppliers perceive risk in $\mathrm{C} 2 \mathrm{C}$ ecommerce transactions, by applying the psychometric paradigm and, more specifically, identify the structure and relationships of three kinds of risk characteristics referred in former research, anxiety characteristics, controllability characteristics, and finally predictability characteristics. Anxiety characteristics reflects suppliers' worry about risk sources; controllability characteristics means suppliers' ability to intervene risk sources [14], and predictability implies suppliers' familiarity with risk sources. Apart from the relationship of the three risk characteristics, this empirical study also includes exploratory factor analysis to achieve individual suppliers' risk sources of the three risk characteristics respectively, and then the relationship between their coping risk behaviors and risk perception in order to get better understand of individual suppliers' risk perception and achieve greater electronic marketing effectiveness by adopting some marketing strategies to improve their interest in $\mathrm{C} 2 \mathrm{C}$ transactions of China.

Besides, both controllability characteristics and predictability characteristics are relative to risk management according to the risk perception structure, so the two risk characteristics are supposed to fall into one dimension while anxiety characteristics remains to be independent. We also suppose that controllability has the most effect on total risk for its importance on risk management.

\section{METHOD}

The research includes two sections, first we develop and revise the questionnaire based on literature review and indepth interview, and then 174 participants were recruited to participate to fill in the questionnaire, and we'll introduce the two sections in more detail subsequently. We get 16 risk sources in $\mathrm{C} 2 \mathrm{C}$ e-commerce transaction according to literature review and in-depth interview. Concretely, in the in-depth interview, we have interviewed ten individual suppliers who each have managed some online shops for more than one year, and they were asked to tell about what risks they had faced, risk characteristics of e-commerce and what kinds of risk management behavior they had adopted. Then a questionnaire was developed based on the 16 risk sources obtained in literature review and in-depth interview mentioned above. The questionnaire has four different sets of data. In the first set, the respondents were asked about their overall online shop management and operating activities. The second set evaluates the impact of the 16 risk sources on three risk characteristics, which are anxiety characteristics, controllability characteristics and predictability characteristics, respectively. We also apply 5-point Likert scale, and each statement is associated with 5-point scales ranging from 1 (very little) to 5 (very much) to evaluate the total risk. The third and fourth parts ask some detailed coping risk behaviors and demographic questions.

174 individual supplier participants in the aggregate were recruited through announcements on well-known Internet forums and $\mathrm{C} 2 \mathrm{C}$ sites in China. $55.7 \%$ are male, $77.0 \%$ are between 20 to 30 years old, $64.8 \%$ individual suppliers started with $\mathrm{C} 2 \mathrm{C}$ transactions in 2003 , and $17.7 \%$ complete more than 10 deals a month, and $36.7 \%$ individual suppliers mostly focus on secondhand goods.

\section{RESULTS}

\section{A. Effect of the Three Risk Characteristics on Total Risk}

The data from the impact of the 16 risk sources on three risk characteristics and total risk were analyzed in the context 
of a stepwise regression. Mean values of 16 risk source items were computed to represent the three risk characteristics scores respectively. Then we examine the basis for the total risk. We expect total risk to be based primarily on the three mean risk characteristics, and we take the stepwise regression analysis in which the three mean risk characteristics scores serve as independent variables and total risk as dependent variable (see table I).

TABLE I

STEPWISE REGRESSION ANALYSIS

\begin{tabular}{cccc}
\hline IV & $\beta$ & $\mathrm{t}$ & Sig. \\
\hline anxiety & 0.43 & 3.17 & $<0.001$ \\
controllability & -0.38 & -2.44 & 0.02 \\
predictability & -0.34 & -2 & 0.04 \\
\hline
\end{tabular}

The regression results indicate that the adjusted $R^{2}=0.598$, $p<0.01$, which means $59.8 \%$ of total risk variance can be explained by the three risk characteristics. As we can see in the table1, total risk is significantly predicted by all of the three risk characteristics. Anxiety characteristics has the most significant effect on total risk, $\beta=0.43$, and it has the greatest influence on total risk, and then controllability characteristics has less significant effect, $\beta=-.38$, and predictability characteristics has the least significant effect, $\beta=-.34$. So the hypothesis that controllability has the most effect on total risk is not proved. The more important role of anxiety characteristics and controllability characteristics on total risk will be examined in a more detailed way, and the relationships and the structure of the three risk characteristics will be discussed below.

\section{B. Relationship of the Three Risk Characteristics}

To look into the relationship of the three risk characteristics, we calculate the 16 risk source items correlations of the three risk characteristics, and then adopt the mean scores to calculate correlations among the three risk characteristics (see table II).

The table II shows that there are only three significant negative correlations between anxiety characteristics and controllability characteristics, so are between anxiety characteristics and predictability characteristics, while there are significant high positive correlations of all the 16 risk source items between controllability characteristics and predictability characteristics. Moreover, there is a significant correlation between the mean risk source scores of controllability characteristics and predictability characteristics, while the other two correlations are not significant. Consistent with the prediction of the controllability characteristics and predictability characteristics to fall into one dimension, we can conclude that controllability characteristics and predictability characteristics have much stronger relationship than with anxiety and the two risk characteristics can be composed to one dimension, which comes down to controllability characteristics. Anxiety characteristics remain to be independent. Thus it proves the hypothesis we propose above. So we will focus on risk source factors of individual suppliers on both anxiety characteristics and controllability characteristics.

TABLE II

CORRELATIONS BETWEEN THE THREE RISK CHARACTERISTICS

\begin{tabular}{lccc}
\hline \multicolumn{1}{c}{ Items } & A.vs.C. & A.vs.P. & C.vs.P. \\
\hline 1 overstock & -0.01 & -0.08 & $.73^{* *}$ \\
2 unfit for sale on the internet & -0.04 & -0.06 & $.39^{* *}$ \\
3 no updated information & $-.30^{* *}$ & -0.12 & $.28^{* *}$ \\
4 medium of exchange fail & -0.09 & -0.01 & $.56^{* *}$ \\
5 no exact product introduction & 0.06 & 0.14 & $.27^{* *}$ \\
6 no update product information & -0.03 & 0.1 & $.56^{* *}$ \\
7 wrong indent & -0.06 & -0.11 & $.46^{* *}$ \\
8 not interact with buyers & 0.05 & -0.04 & $.37^{* *}$ \\
9 buyer don't talk with supplier & -0.11 & -0.04 & $.58^{* *}$ \\
10 slack communication & -0.09 & -0.03 & $.47^{* *}$ \\
11 shipping \& returns after trade & -0.05 & $-.21^{* *}$ & $.43^{* *}$ \\
12 logistics delay & -0.02 & $-.23^{* *}$ & $.49^{* *}$ \\
13 payment delay & -0.08 & $-.20^{* *}$ & $.58^{* *}$ \\
14 shipping \& returns for times & -0.13 & -0.14 & $.35^{* *}$ \\
15 ill buyers & $-.28^{* *}$ & -0.05 & $.53^{* *}$ \\
16 buyers don't trust online shop & $-.17^{* *}$ & 0.06 & $.48^{* *}$ \\
Mean risk source score & -0.11 & -0.06 & $.63^{* *}$ \\
\hline No $* 05 ; * .01 ;$ & & &
\end{tabular}

Note: $* p<.05 ; * * p<.01$;

A-Anxiety; C-Controllability; P-Predictability

\section{Risk Source Factors of Anxiety Characteristics}

Insights into the risk sources of the anxiety characteristics were provided by adopting exploratory factor analysis, and we get four risk source factors of anxiety characteristics, cumulative percent of variance explained is $69.51 \%$. To make sense of the four risk source factors, we check the items the four factors include. They are named delivery and payments aspect, communication aspect, information presentation aspect and stocking up aspect according to the meaning of contained items respectively (see table III).

TABLE III

RISK SOURCE FACTORS OF ANXIETY CHARACTERISTICS

\begin{tabular}{cccc}
\hline Risk source factor & Eigenvalue & $\begin{array}{c}\text { Variance } \\
\text { explained }\end{array}$ & $\begin{array}{c}\text { Items } \\
\text { contained }\end{array}$ \\
\hline $\begin{array}{c}\text { Delivery and } \\
\text { payment }\end{array}$ & 5.51 & 39.35 & $11-15$ \\
$\begin{array}{c}\text { Communication } \\
\text { Information } \\
\text { present }\end{array}$ & 1.68 & 11.99 & $8,9,10$ \\
Stocking up & 1.48 & 10.57 & $4,5,6,7$ \\
\hline
\end{tabular}

\section{Risk Source Factors of Controllability Characteristics}

Applying the same process with the above risk sources factor analyze, we get three risk source factors of controllability characteristics with exploratory factor analysis. 
The cumulative percent of variance explained is $63.26 \%$. The three risk source factors are named consumer aspect, agency aspect and inner management aspect with the examination of the items contained respectively (see table IV).

TABLE IV

RISK SOURCE FACTORS OF CONTROLLABILITY CHARACTERISTICS

\begin{tabular}{cccc}
\hline Risk source factor & Eigenvalue & $\begin{array}{c}\text { Variance } \\
\text { explained }\end{array}$ & $\begin{array}{c}\text { Items } \\
\text { contained }\end{array}$ \\
\hline Consumer & 6.2 & 38.76 & $9,11,14,15,16$ \\
Agency & 2.82 & 17.64 & $4,12,13$, \\
Inner management & 1.1 & 6.86 & $1,2,7,8,10$ \\
\hline
\end{tabular}

\section{E. Impact of Risk Source Factors of Anxiety and} Controllability Characteristics on Total Risk

The data were analyzed in the context of a regression model using the four risk source factors of anxiety characteristics and three risk source factors of controllability characteristics as independent variables and individual suppliers' total risk as dependent variable (see table V). Results shows that the adjusted $R^{2}=0.542, p<0.01$, which means $54.2 \%$ of total risk individual suppliers perceived can be explained by the four risk source factors of anxiety characteristics and three risk source factors of controllability characteristics. Reassuringly, analyses also revealed that total risk can be predicted by anxiety and controllability characteristics, and the adjusted $R^{2}$ change is tiny compared to the three risk characteristics predicting total risk mentioned above. Thus, the hypothesis controllability characteristics and predictability characteristics can be composed to one dimension while anxiety characteristics remain to be independent is proven once again.

TABLE V

EFFECTS OF Fisk SOURCE FACTORS ON TOTAL RISK

\begin{tabular}{cccc}
\hline IV & $\beta$ & $\mathrm{t}$ & Sig. \\
\hline Stocking up & 0.04 & 0.84 & 0.61 \\
Information present & 0.16 & 2.17 & 0.03 \\
Communication & 0.14 & 1.6 & 0.05 \\
Delivery and payment & 0.22 & 3 & $<0.001$ \\
Consumer aspect & -0.19 & -2.64 & 0.01 \\
Agency aspect & -0.15 & -2.14 & 0.04 \\
Inner management & -0.05 & -0.67 & 0.5 \\
\hline
\end{tabular}

F. Relationship between Coping Risk Behavior and Risk Characteristics

To provide more evidence for the relationship between coping risk behaviors and risk characteristics, we focus on 12 kinds of coping risk behavior that individual suppliers may take (see table VI). We calculate frequency that every coping risk behavior is taken. The one that is fewest taken is "only transacting with buyers in the same city or not far away", which indicates convenience advantage of e-commerce and $\mathrm{C} 2 \mathrm{C}$ e-commerce tends not to be influenced by space. The top five kinds coping risk behavior mostly taken are detailed introduction with illustration, interacting with buyers actively, making the final affirmance before transaction, looking over buyers' information carefully, and posting information on many sites. The above five coping risk behaviors almost become default behaviors that individual suppliers will take in the $\mathrm{C} 2 \mathrm{C}$ transactions, and another six kinds of coping risk behavior are also taken by more than half of the individual suppliers. Thus, individual suppliers tend to take coping risk behaviors as many as possible to avoid financial and security risk problems.

Apart from examining the general view of coping risk behaviors individual suppliers take, we also want to verify whether there are differences in anxiety characteristics and controllability characteristics between individual suppliers who take a specific coping risk behavior and who don't. So we differentiate individual suppliers into two groups according to whether they take the specific coping risk behavior, and then take total score of anxiety characteristics and controllability characteristics as dependent variable, apply T-test respectively (see table VI).

TABLE VI

CONNECTION OF COPING RISK BEHAVIORS AND RISK CHARACTERISTICS

\begin{tabular}{|c|c|c|}
\hline Coping risk behavior & Anxiety $t$ & Controllability $t$ \\
\hline $\begin{array}{l}1 \text { Detailed introduction with } \\
\text { illustration }\end{array}$ & -0.09 & 0.66 \\
\hline $\begin{array}{l}2 \text { Interacting with buyers } \\
\text { actively }\end{array}$ & 0.98 & $1.98 *$ \\
\hline $\begin{array}{l}3 \text { Making final transaction } \\
\text { affirmation }\end{array}$ & $-1.80^{*}$ & $1.80^{*}$ \\
\hline $\begin{array}{l}4 \text { Checking buyers' } \\
\text { information }\end{array}$ & $2.93 * *$ & $2.09 *$ \\
\hline $\begin{array}{l}5 \text { Posting information on many } \\
\text { sites }\end{array}$ & 0.32 & -0.58 \\
\hline $\begin{array}{l}6 \text { Low price to the best of one's } \\
\text { abilities }\end{array}$ & 0.49 & -0.59 \\
\hline $\begin{array}{l}7 \text { Claim no responsible for } \\
\text { latent matter }\end{array}$ & 0.4 & $-2.15^{*}$ \\
\hline $\begin{array}{l}8 \text { Choosing time and address } \\
\text { actively }\end{array}$ & -0.43 & 1.35 \\
\hline $\begin{array}{l}9 \text { Sales online as well as off- } \\
\text { internet }\end{array}$ & 0.27 & 1.1 \\
\hline $\begin{array}{l}10 \text { Only transacting with } \\
\text { sincere buyers }\end{array}$ & $-2.31 *$ & $1.83 *$ \\
\hline 11 Exchanging reputation & $-2.51 * *$ & 0.49 \\
\hline $\begin{array}{l}12 \text { Transact with buyers of the } \\
\text { same city }\end{array}$ & -1.34 & 0.28 \\
\hline
\end{tabular}
Note: ${ }^{*} p<.05 ; * * p<.01$.

Concretely, the individual suppliers who have make the final transaction affirmation, only transact with sincere buyers and exchange reputation with consumers feel lower anxiety risk characteristics than those who don't take the above coping risk behaviors. But the participants who check buyers' information carefully feel higher anxiety risk level than those 
who don't, and the other coping risk behaviours have no significant effect on anxiety risk characteristics.

On the other hand, the individual suppliers who interact with buyers actively, make the final transaction affirmation, check buyers' information carefully, and only transact with sincere buyers feel significant higher control level of risk than those who don't take the above coping risk behaviors. But those who claim no responsible for latent matter will feel less controllability of risk than those who don't, and the other coping behaviors have no significant effect on controllability risk characteristics level.

\section{DISCUSSION}

The research reports in this manuscript seeks to bring a better understanding of the three risk characteristics and risk source of individual suppliers in $\mathrm{C} 2 \mathrm{C}$ e-commerce transactions. We consider three kinds of common risk characteristics that formal researchers have proposed: anxiety, controllability and predictability, and focus on them together at the same time. The results suggest that, anxiety characteristics has the most significant effect on total risk, and then controllability characteristics has less significant effect, which is ignored by the former researches on suppliers' risk perception. The prior researches mostly focus on "anxiety", but we prove that "controllability" is also important to understand suppliers' risk perception. Furthermore, risk management start with controlling the risk. The research provides evidence for both anxiety and controllability characteristics similarities and differences in the risk perception, the two risk characteristics have significant influence on total risk, but their risk sources are distinct.

The primary focus of the current research lay in examining the risk characteristics structure, and the results also suggest that, there is high correlation between "controllability" and "predictability", while "anxiety" is relatively independent with them. Because of the high correlation between controllability characteristics and predictability characteristics as well as the smallest effect that predictability characteristics has on total risk, we consider that there is no need to pay further attention on predictability characteristics, and we can better understand the risk perception of the individual suppliers during the $\mathrm{C} 2 \mathrm{C}$ transaction starting with "anxiety" and "controllability" risk characteristics, and it is in accordance with our prediction.

Then we pay further attention on the two risk characteristics to explore suppliers' risk sources, and find that risk source factors of anxiety characteristics are different from risk source factors of controllability characteristics. According to exploratory factor analysis, we find that during the $\mathrm{C} 2 \mathrm{C}$ transaction, the individual suppliers worry about the risk comes from four aspects, which are stocking up, information presentation, communication and delivery and payment. It means that they worry about risk arise from the total transaction process. Individual suppliers control the risk from three aspects, that is, consumer, agency and inner management, and the three aspects fall into interaction process. It means that they consider various interacting partners much more relative to the transaction process to control the risk. Hence the multi-dimension of risk perception is proved, anxiety and controllability risk characteristics is composed of different risk sources.

Specifically, when focus on individual suppliers' perceived risk with multi-dimension, we can get better and deeper understand of individual suppliers' perceived risk they may encounter during $\mathrm{C} 2 \mathrm{C}$ transaction and then risk management. For example, if one needs to reduce individual suppliers' worry about transaction risk, he must start with the four transaction processes, that is stocking up, information presentation, communication and delivery and payment; if one needs to enhance the controllability of risk that individual suppliers face, he should start with three kinds of transaction relative interacting partners, that is, consumer, agency and inner management.

Among the four aspects individual suppliers worry about, risk coming from information presentation, communication, delivery and payment have significant effect on total risk. In other words, if we can play down anxiety from the three aspects, we can reduce total risk significantly. So individual suppliers is suggested putting more detailed product introduction, communicating and interacting more actively with consumers, and applying more reliable delivery and payment systems to reduce anxiety and total risk perception. Furthermore, the controllability from consumer and agency has significant effect on total risk, so we can reduce total risk significantly by better controlling risk from consumer and agency.

Relationship between coping risk behavior and risk characteristics shows individual suppliers tend to take the coping risk behaviors as many as possible. But only part of the coping risk behaviors has significant correlation with risk perception. Furthermore, different kinds of coping risk behavior will be taken according to different risk characteristics, either to reduce anxiety or to get more control of risk. Affirming and looking over buyers' information before transaction carefully, only transacting with sincere buyers, and exchanging reputation are relative to anxiety characteristics, that is, individual suppliers who take the above coping risk behaviors will feel different level of anxiety than those who don't take; Interacting with buyers actively, making the final affirmance before transaction, looking over buyers' information carefully, clean the slate for potential matter, and only transacting with sincere buyers are relative to controllability characteristics, that is individual suppliers who take the above coping risk behaviors will feel different level of control of risk than those who don't take. But there is no causal relationship between coping risk behavior and risk characteristics, and further research is needed.

As we mentioned in the introduction section, there are still some problems and security risk which sellers in the $\mathrm{C} 2 \mathrm{C}$ ecommerce transactions must bear. Prior to developing a risk management plan in $\mathrm{C} 2 \mathrm{C}$ e-commerce transactions, it is important to clearly understand the perception of risk among individual suppliers. Such understanding will substantially improve communication and online shop management status 
of the individual suppliers in $\mathrm{C} 2 \mathrm{C}$ e-commerce transactions, resulting in the emergence of a better risk management plan. In addition, this research makes several contributions, particularly with regard to the existing literature on risk perception and e-commerce risk management. Our research provides insights into the influence of the three risk characteristics on the total risk; specifically, our finding shows that both anxiety and controllability characteristics have crucial impact on total risk, and what risk sources drives these risk characteristics. Finally, the research identifies the connection between coping risk behaviors and anxiety and controllability characteristics at a more detailed level. So our research provides the relationship between risk perception and risk management for individual suppliers and Internet service providers in both further theoretical and practical way.

As noted earlier, the current research fails to get more detailed information of coping risk behaviors and risk characteristics, and there is no casual relationship between them. Thus future research in the area could investigate additional relationship of risk characteristics and risk management in $\mathrm{C} 2 \mathrm{C}$ e-commerce transactions, and indeed more transaction circumstances. More detailed answers to risk perception in e-commerce would furnish us with increased theoretical and practical knowledge in an area of consumer research and Internet management that has not received adequate attention over the years.

\section{CONCLUSION}

The research shows that:

During the $\mathrm{C} 2 \mathrm{C}$ transaction, the individual suppliers worry about the risk from four aspects, that is, stocking up, information presentation, communication and delivery and payment. They control the risk from three aspects, that is, consumer, agency and inner management; Different risk characteristics have different risk source factors; Controllability characteristics and predictability characteristics can compose to one dimension, and anxiety characteristics can be another relatively independent dimension. For better understanding of the risk perception of the individual suppliers during the $\mathrm{C} 2 \mathrm{C}$ transaction, we analyze anxiety characteristics and controllability characteristics.

The anxiety characteristics about the risk rise from information presentation, communication and delivery and payment, and the controllability of the risk come from consumer and agency. All the risk sources can significantly influence the total perceived risk.

Individual suppliers tend to take the coping risk behaviors as many as possible. Only part of the coping risk behaviors has significant influence on anxiety characteristics and controllability characteristics.

\section{ACKNOWLEDGMENT}

This study is founded by the Knowledge Innovation Project of the Chinese Academy of Sciences (Grant NO.KSCX2-YWR-130) and special fund for co-construction project of Beijing Education Council. The corresponding author is Yiwen Chen, and his available e-mail is chenyw@psych.ac.cn. The authors wish to thank Shuangshuang Li for her helpful comments and literature review preparation.

\section{REFERENCES}

[1] J. P. Fang. (2004) Webpage on ENET. [Online]. Available: http://www.enet.com.cn/cio/inforcenter/A20030717253578.html (in Chinese)

[2] X. F. Xie, and L. C. Xu. "A review on risk perception and theory frames (in Chinese)," Journal of Developments in Psychology., vol. 13, pp. 17-22, Apr. 1995.

[3] S. Mun, "The perception of risk in sport activities," Doctor. thesis, College of Education, Florida, USA, Jun. 2004.

[4] A. de. Blaeij, and D, van. Vuuren, "Risk Perception of Traffic Participants," Accident Analysis and Prevention., vol. 35, pp. 167-175, May. 2001.

[5] C. Starr, "Social Benefit versus Technological Risk," Science., vol. 165, pp. 1232-1238, Sep. 1969

[6] F. N. Laird, "The decline of deference: The political context of risk communication," Risk Analysis., vol. 9, pp. 543-550, May. 1989.

[7] S. Krimsky and A. Plough, Environmental hazards: Communicating risks as a social process: Auburn House Dover, MA, 1988.

[8] S. Oltedal, B. E. Moen, H. Klempe, and T. Rundmo, "Explaining risk perception: An evaluation of cultural theory," Trondheim: Norwegian University of Science and Technology., vol. 85, pp. 1-33, Apr. 2004.

[9] D. Kahneman and A. Tversky, "Prospect theory: An analysis of decision under risk," Econometrica., vol. 47, pp. 263-291, Mar. 1979.

[10] A. Tversky and D. Kahneman, "Advances in prospect theory: Cumulative representation of uncertainty," Journal of Risk and uncertainty., vol. 5, pp. 297-323, Oct. 1992.

[11] N. Stewart, N. Chater, H. P. Stott, and S. Reimers, "Prospect relativity: How choice options influence decision under risk," Journal of Experimental Psychology-General., vol. 132, pp. 23-45, Mar. 2003.

[12] P. Slovic, B. Fischhoff, and S. Lichtenstein, "Behavioral decision theory perspectives on risk and safety," Acta Psychologica., vol. 56, pp. 183-203, Aug. 1984.

[13] B. Fischhoff, P. Slovic, S. Lichtenstein, S. Read, and B. Combs, "How safe is safe enough? A psychometric study of attitudes towards technological risks and benefits," Policy Sciences., vol. 9, pp. 127-152, Apr. 1978.

[14] Z. U. Ahmed, O. Mohamad, B. Tan, and J. P. Johnson, "International risk perceptions and mode of entry: a case study of Malaysian multinational firms," Journal of Business Research., vol. 55, pp. 805813 , Oct. 2002. 